University of Massachusetts Amherst ScholarWorks@UMass Amherst

Masters Theses 1911 - February 2014

1963

\title{
The partial reinforcement effect sustained through blocks of continuous reinforcement in classical eyelid conditioning.
}

Sally Lou Perry

University of Massachusetts Amherst

Follow this and additional works at: https://scholarworks.umass.edu/theses

Perry, Sally Lou, "The partial reinforcement effect sustained through blocks of continuous reinforcement in classical eyelid conditioning." (1963). Masters Theses 1911 - February 2014.1871.

Retrieved from https://scholarworks.umass.edu/theses/1871

This thesis is brought to you for free and open access by ScholarWorks@UMass Amherst. It has been accepted for inclusion in Masters Theses 1911 -

February 2014 by an authorized administrator of ScholarWorks@UMass Amherst. For more information, please contact

scholarworks@library.umass.edu. 
THE PARTIAL REINFORCEMENT EFECT SUSTANEQ THROUGH BL OCKS OF CONTINUOUS RENFOROENENT W CLASIGAL EYELD CONOHONING 
The Partial Reinforcement iffect Sustained Through Blocks of Continuous Reinforcement in Classical

Eyelid Conditioning

Sally L. Perry

Thesis Submitted in Partial Fulfillment

of the Degree of Naster of Science

University of Massachusetts

Amherst

1963 
tist of figures

List of appendix tables

iㅗ

Introduction

Method

Subjects and design

Apparatus and rethod of recording

Conditioning procedure

Response measures

Rosults

Bxtinction

Intortrial blink rate

Discussion

Extinction

Intortrial biink rato

Summary

Reforences

Appendix A

Appendix C

Appendix D

Appendix

$20 \quad a-c$

Acknowlodgerments 
Ist of rines

Bigure

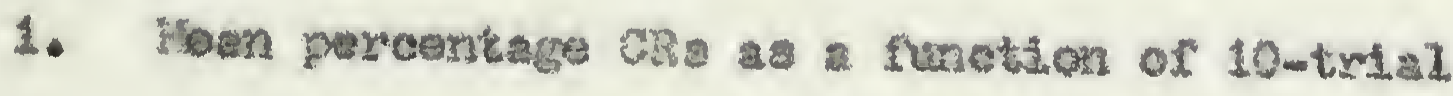

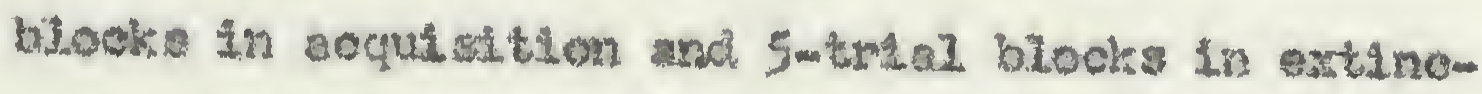

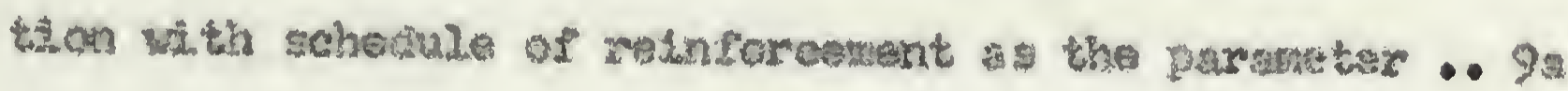


List of Appendix Tables

Appendix

Page

A Instructions

B F-ratios frora analyses of variance and coveriance

of arcsine percentage on-txial responding in acquisition

C F-ratios from analyses of variance and covariance

of arcsine percentage on-trial sesponding in extinction

D F-ratios from analysos of variance of aresine porcontage intertrial responding

Ea Percentage CRs and intortial responses (BR) for subjects in Group 50-50

Eb Percentage CRs and intertrial responses (BR) for subjects in Group 50-100

De Percentage CRs and intertrial responses (BR) for subjects in group 100-100 
The purpose of this study was to investigate the effect of a shift from partial to continuous reinforcement in acquisition upon resistence to extinction in classical eyelid conditioning.

In 1939 Humphreys demonstrated that in eyelid conditioning with human Ss resistence to extinction following partial reinforcement is superior to that following continuous reinforcement and proposed a discrimination hypothesis to account for this finding. According to the discrimination hypothesis, resistence to extinction is inversely related to the degree of discriminability of the shift from the acquisition to the extinction situation. An essential feature of this theory is the notion that the S's performance in extinction depends upon his anticipation of reinforcement or nonreinforcement. The contrast between continuous reinforcement in acquisition and no reinforcement in extinction is presumably optimal for a change in expectation and produces a sudien decrement in responding during extinction whereas the contrast between partial reinforcement in acquisition and no reinforcement in extinction is not optimal. The S learns to expect that periods of nonreinforcement will be followed by periods of reinforcement, and, therefore, he continues to respond for longer periods of time during extinction than he rould if he had been trained under continuous reinforcement. The partial reinforcement effect (PRE) has since been obtained in several eyelid conditioning experiments ( Hake and Grant, 1951; Grant and Hake, 1951; Grant and Schipper, 1952; Grant, Schipper, and Ross, 1952; Martman and Grant, 1960: Froseth and Grant, 1961).

Grant, Riopelle, and Hake (1950), using magnitude as a measure 
of responding (Humphreys, 1943), found extinction following single and double altermation of reinforced and nonreinforced trials to be similar to extinction following $100 \%$ reinforcement, whereas extinction following random intermittent reinforcement was described by a different function. Presumably, the single and double alternation groups as well as the $100 \%$ reinforcement group were able to verballze the pattern of reinforcement whereas this was not possible for the partial reinforcement group. According to the discrimination hypothesis, the shift from acquisition to extinction would be more pronounced for the groups which were able to verbalize the reinforcement pattern.

Moore and Gormezano (1963), using omitted- and delayed-ucs groups in aequisition (McAllister, 1953; Ross, 1959), found that the delayed-UCS group extinguished more rapidly under $0 \%$ reinforcement than did the omitted-UCS group. These results can be interpreted as supporting the discrimination hypothesis. The shift from acquisition to extinction was more pronounced for the delayed-UCS group since the CS was always followed by the JCS in acquisition. whereas in extinction the CS was never followed by the UCS. On the other hand, the omitted-UCS group received both UCS and non-UCS trials during acquistion, and, consequently, the discrimination between acquisition and extinction was more difficult to make.

A cognitive approach has recently been taken by Spence in interpreting rate of extinction as a function of the change in conditions from acquisition to extinction. Spence (1963) found that resistence to extinction for Ss trained under continuous reinforce- 
ment and extinguished with delayed-UCS was higher than for Ss extingui shed under omitted-UCS conditions. Further, Ss who were given a probability-leaming task simultaneously with conditioning and were extinguished with a delayed-uCs were more resistent to extinction than either the omitted-UCS group or the delayed-UCS group which had not been given an additional learning task. The additional learning task presumably served to minimize the awareness of the change in conditions from acquisition to extinction. Spence's version of the discrimination hypothesis, which is almost identical with Fumphreys' original statement, is presented in Spence, Rutledge, and Talbott (1963).

According to the discrimination hypothesis, a block of continuously reinforced trials interpolated between a series of partially reinforced trials and extinction should increase the discriminability between the training and extinction situations and should, therefore, lead to a larger decrement in responding than would be observed if the block of continuous trials were not interpolated immediately prior to extinction. A number of studies have tested this prediction. Quartermain, Vaughan, and Mangan (1961) trained rats under partial and partial-continuous reinforcement schedules and found that the partial-continuous group was more resistent to extinction than the partial group. In order to test the prediction that a shift in reinforcement schedule may have been the crucial variable, Quartermain and Vaughan (1961) trained rats under 10-100\%, 10-25\%, and 10-10\% reinforcement schedules and found no differences among groups in extinction. Clearly these results do not support the discrimination hypothesis. Jenkins (1962) found that with 
pigeons in a free-responding situation, abruptness of the change in reinforcement schedule from training to extinction did not affect resistence to extinction. Instead, the PRE persisted in spite of a period continuous reinforcement inmediately preceding extinction. Theois (1962) found essentially the same results with rats in a runway situation. In this experiment, two groups received different amounts of continuous reinforcement throughout acquisition, two groups received $50 \%$ reinforcement followed by different amounts of continuous reinforcement, and a fifth group received $50 \%$ reinforcement throughout acquisition. It was found that in spite of the continuous reinforcement immediately before extinction, rats trained under partial reinforcement were all more resistent to extinction than those trained only under continuous reinforcement. In a noncontingent two-choice probability-leaming task the effects of shifts in reinforcement schedule upon resistence to extinction were investigated by Capaldi and Capaldi (1963). Again it was found that any group having received partial reinforcement at any time was more resistent to extinction than a group which never received partial reinforcement. Taken together these experiments indicate that the abruptness of the transition in reinforcement schedule from acquisition to extinction cannot entirely explain the PRE, and, therefore, the adequacy of the discrimination hypothesis must be questioned.

Since the evidence against the discrimination hypothesis comes from studies of instrumental conditioning using an interpolated $100 \%$ reinforcement design, it was the purpose of the present study 
to determine whether the discrimination hypothesis can at least be applied to human classical conditioning or if it must be modified or abandoned in favor of a theory of partial reinforcement which eruphasizes possible long-lasting effects of nonreinforcement (Lawrence and Festinger, 1962). 
Method

Subjects and design. A total of 81 students from introductory and summer psychology classes and volunteers at the University of Massachusetts served as S.s. Group 50-50 received 50 per cent partial reinforcement throughout a.11 80 acquisition trials. Group 50-100 received 50 per cent partial reinforcement during the first 40 acquisition trials and was shifted to 100 per cent reinforcement for the remaining 40 trials. Group 100-100 received 100 per cent reinforcement for all 80 acquisition trials. Three Ss from each group were eliminated for failure to give at least three conditioned responses in the last block of 10 acquisition trials. Of the remaining 72 Ss, 12 were randomly assigned to each of six cells in a $3 \times 2$ factorial design where schedule of reinforcement and sex represented the dimensions of the experiment. In addition to 80 acquisition trials, all groups received 20 extinction trials with no UCS.

Apparatus and method of recording. The $S$ tas seated in a dental chair in a $6^{\prime} \times 7^{\prime} 5^{\prime \prime}$ well-illuminated room. The conditioned stimulus (CS) consisted of an $800 \mathrm{cps}$ tone of $70 \mathrm{db}$ SPL provided by a HewlettPackard audio-oscillator. The unconditioned stimulus (UCS) was an air puff of $1.0 \mathrm{Ib} / \mathrm{sq}$ in pressure delivered to the right eye by means of a nozzle attached to the headset worm by $\underline{S}$. The duration of the stimuli and the interval between them was controlled by Hunter interval timers, and the intertrial interval was automatically controlled by a Grayson-Stadier interval prograrmer. The apparatus was situated in a room adjoining the experimental room; any noise 
resulting from the equipment was masked by a 66 db SPL noise provided by a fan located in the experimental room.

The S's eyelid movements were measured by a combination of mechanical and electrical means. A light-weight aluminum lever was attached to S's eyelid with adhesive tape. This was connected by a piece of light-weight, stiff wire to the rotating arm of a microtorque potentiometer located on the headset $S$ wore. A tension spring attached to this arm maintained the wire in a taut position so that up and down movements of the eyelid were recorded but restriction of eyelid movement was minimal. The movement of the eyelid and subsequent movements of the potentiometer arm produced a signal which was amplifled by a Hunter eyeblink amplifier so as to operate an oscillographic pen motor. During a trial, the recording paper moved through a Brush recorder at the rate of $120 \mathrm{~mm} / \mathrm{sec}$. An additional recorder ran continuously at a rate of $5 \mathrm{~mm} / \mathrm{sec}$ to provide a measure of intertrial responding.

Conditioning procedure. A set of "neutral" instructions (Gormezano and Moore, 1962) was administered to $S$ inmediately before the first trial. On reinforced trials, the CS was presented for 550 msec and terminated together with a $50 \mathrm{msec}$ UCS. On nonreinforced trials, the CS was presented without the UCS for 550 msec. A 50 per cent reinforcement schedule was employed for partiallJ reinforced groups and was restricted such that no more than four nonreinforced trials occurred consecutively and such that within each block of 10 trials there were an equal number of reinforced and nonreinforced trials. The intertrial intervals were 15.0, 22.5, and $30.0 \mathrm{sec}$, 
randomly distributed.

Response moasures. The criterion for a condtitioned response (CR) was any derlection of the recording pen of at least one mm froin the baseline and occurring in the katancy rainge of 150-500 msec after the onset of the CS.

Intertrial responses were measured in order to adjust conditioning scores for S's operant level of responding. The criterion for an intertrial response was any excursion and return of the recording pen of at least one mo. The blink rate ror each intertrial interval was obtained by adding up the number of blinks in the interval and dividing by the number of successive 500-msec segments within that interval. Under the assumption that each 500-msec segment can contain no more than one response, this procedure permitted the percentage intertrial blink rate to be placed on the same scale of measurement as percentage CRs. 
Fesults

Figure 1 presents the percentage CRs for the three groups over blocks of 10 accuisition trials and subsequent blocks of 5 extinction trials. The first point on each curve refers to the percentage CRs on trial 1. As may be seen, group 100-100 conditioned at a faster rate and reached a higher asymptote than did groups 50-50 and 50-100; the final level of conditioning for group 100-100 was 79 per cent. During the first half of acquisition. group 50-50 conditioned at a fester rate and reached the 54 per cent lovel by trial-block 4. while Eroup 50-100 conditioned more slowly and reached only the 40 per cent level at this point. However, during the last half of acquisition group 50-100, upon being shifted to continuous reinforcement, reached the 61 per cent level within 10 trials and a final level of 64 per cent, an increase of ondy 10 per cent over the last 40 trials.

The level of extinction responding was highest for group 50-50 and lowest for group 100-100. Group 50-100 extinguished at a level approximately haliway between groups 50-50 and 100-100. The rate of extinction was about tho same for all groups. The sharpest drop in responding occurred during the first 10 trials of extinction and was followed by a slower decrease for the remaining 10 trials.

Extinction. For statistical analyses an aresine transformation was applied to the following data: (a) percentage CRs for all 80 acquisition trials (b) percentage CRs for the last 40 acquisition trials (c) percentage CRs in extinction (d) percentage intertrial 


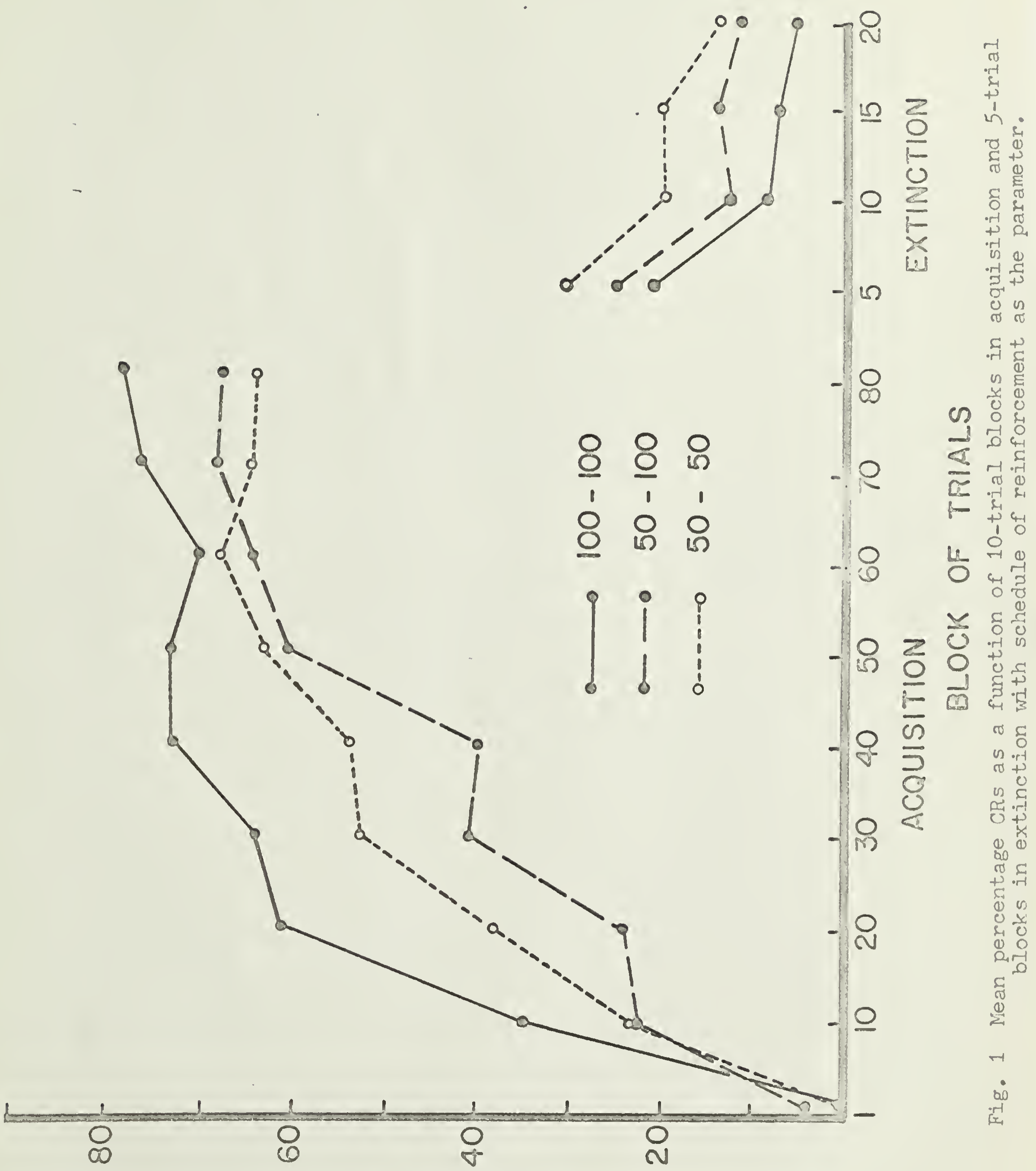

SYO LNヨJ43d 
responding during acguisition and (e) percentage intertrial responding during axtinction. These measures will subsequently be referred to as (a) acquisition scores (b) asyrototic acquisition scores (e) extinction scores (a) blink rate in acquisition and (e) blink rate in extinction, respectively.

An analysis of variance performed on extinction scores yielded a stgnificant main effect due to schedule of reinforcement in acquistion $(F(2,66)=3.91, p<.05)$. When extinction scores were adjusted for acquisition scores by an analysis of covariance, schedule of rainforcenent was highly significant $(F(2,65)=11.37, p<.001)$. When extinction scores were adjusted for both acquisition scores and blink rate during extinction. schedule of reinforcent was again highly significant $(F(2,63)=12.97, p<.001)$

Since the nsymptotic scquisition scores might be considered the more appropriate covariate adjustment in extinction, an analysis of coveriance using this weasure and blink rate in extinction as the covariates was performed. A signiflcant min effect due to schedule of reinforcement $(F(2,63)=11.26, p<.001)$ was obtalned.

Individual comparisons were made between the adjusted means of the extinction scores of groups $50-50 \mathrm{vs}$. $50-100$ and groups 50-100 vs. 100-100. Using acquisition scores and blink rate in extinction as the covariates, the adjusted means were 42.19. 37.35. and 20.04 for groups 50-50, 50-100, and 100-100, respectfully. The difference between groups 50-50 and 50-100 was 
not signifleant while exoups 50-100 and 100-100 differed signiMcantly from each other $(F(1,63)=15.84, p<.001)$. Using the asymptotic acquisition scores and blink rate in extinction as the covartates, the adjusted means were 37.95 .34 .95 . and 26.99 for groups 50-50, 50-100, and 100-100 respectively. Here group 50-100 did not diffex significantly from either groups 50-50 or 100-100 but group 50-50 differed significantiy from group 100-100 $(1,65)=7.69, p<.01)$

Intertrial blink rate. Intertrial biink rate in acquistion showed no differences among roups $(F(2,65)=.09)$ and. other than a slight decrease early in training. the blink rate remained essentially constant for all groups at about the 20 per cent level throughout ecquisition. Intertrial blink rate in extinction showed no differences among groups $(F(2,65)=.38)$ but a significant difference due to $\operatorname{sex}(F(1.65)=7.01, p<.05)$ with males responding more between trials then females. The average blink rate remained constant at about the 15 per cant level for all groups throughout extinction. Whth respect to the two analyses of covariance perforned on the extinction data. a comperison of the F ratios suggests that either the increased precision or the statistical control obtained by using intertrial blink rate as a covariate was small compared with the precision and control obtained by usirg acquisition scores as a covariate. The average intercell correlation between extinction scores and blink rate in extinction was 23 . 
Discussion

Extinction. The discrimination hypothesis predicted that the group receiving partial reinforcement prior to extinction (50-50) would respond at a signiflcantly higher level during extinction than would the two groups receiving continuous reinforcement prior to extinction (50-100 and 100-100). As predicted, group 50-50 responded at a signiflcantly higher level during extinction than did group 100-100. However, group 50-100 extingui shed at a level approximately halfway between groups 50-50 and 100-100. When extinction scores were adjusted for either the total acquisition scores or for the asymptotic acquisition scores, the adjusted means for group 50-100 were closer to those of group 50-50 than to those of group 100-100.

It would appear that the version of the discrimination hypothesis stated in the introduction is not sufficient to explain the extinction performance of group 50-100 in this experiment. However, if one assumes that resistence to extinction depends not only on S's awareness of the change in reinforcement schedule from acquisition to extinction but on his interpretation of the change in reinforcement, then an expanded form of the discrimination hypothesis might account for the results. The Ss in group 50-100 may interpret the onset of extinction as a reinstatement of partial reinforcement rather than as the start of extinction, and the extent to which such an interpretation is made should increase the level of responding of these Ss relative to those in group 100-100. The Ss in the latter group, having no previous experience with 
cement, could not be expected to interpret the introduction of a partial reinforcement schedule. : blink rate. Intertrial blink rate was found to onstant over trials within both acquisition and is finding agrees with observations of Mattson and However, unlike the Mattson and Moore study, blink wee groups in the present experiment decreased diately after the shift from acquisition to extincrease can be explained by at least two hypotheses Literature on eyelid conditioning. If blink rate is a $D$, the decrease of 5 per cent might be attributed in $D$ as a result of the absence of the UCS in extinc1958). Another explanation might be expressed in alization of inhibition of the ejelid response If the on-trial response is being inhibited during mn this inhibition might generalize to intertrial - hence, cause a decrement in responding. This the more unlikely of the two because if generalion-trial and intertrial stimuli was operating in $t$, then, instead of remaining constant over trials, nking should have increased together with the rves and decreased with the extinction curves. 


\section{Summary}

Two groups of 24 Ss recelved 80 eyelid conditioning trials with a schedule of reinforcement in acquisition of elther $50 \%$ random (group 50-50) or 100\% (group 100-100). A third group of 24 Ss (group 50-100) was shifted from a 50\%-random schedule to $100 \%$ on trial number 40. All three groups recelved 20 extinction trials. According to Fumphreys' discrimination hypothesis. Ss trained under 50-100\%. Iike Ss trained uncer 100\% reinforcement, should discriminate the change in reinforcement schedule between acquisition and extinction more easily than Sis trained under $50 \%$ reinforcement and should, therefore, be significantly less resistent to extinction than the latter group.

The mean extinction scores of the three groups, adjusted by analysis of covariance for elther (a) acquisition scores and intertrial responding during extinction or (b) asymptotic acquisition scores and intertrial responding during extinction, indicated that the extinction performance of group 50-100 was closer to that of group 50-50 than to that of group 100-100. A modified version of the discrimination hypothesis was proposed to account for the result. 
Capaldi, A. E. and Capaldi. E. J. Influence of patterns of events in sequence on resistence to extinction. Psychol. Rep..
1963. 12, 343-347.

Froseth, J. Z. and Crant, D. A. Influence of intermittent reinforcement upon acquistion, extinction, and spontaneous recovery in eyelid conditioning. J. gen. Psychol., 1961, 64, 225-232.

Cormezano, I. and Moore. J.W. Fffects of instructional set and UCS intensity on the latency, percentage, and form of the eyelid response. J. exp. Psychol., 1962,63,487-494.

Grant, D. A. and Fiake, H. W. Dark adaptation and the Ilumphreys random reinforcement phenomenon in human eyelid conditioning. J. exp. Psychol., 1951, 42, 417-423.

Grant, D. A., Riopelle, A. J.. and Hake, H. W. Resistence to extinction and the pattem of reinforcement. I. Alternation of reinforcement and the conditioned eyelid response. J. exp.
Psychol. $1950,40,53-60$.

Grant, D. A. and Schipper, I. M. The acquisition, and extinction of conditioned eyelid responses as a function of the percentage of fixed-ratio random reinforcement. J. exp. Psychol., 1952, 43.

Grant, D. A., Schipper, I. M., and Ross, B. II. Effect of intertrial interval during acquisition on extinction of the conditioned 1952. 44, 203-210.

Hake, H. W. and Grant, D. A. Resistence to extinction and the pattern of reinforcement. II. Erfect of successive alternation of blocks of reinforced and nonreinforced trials upon the conditioned eyelid response to light. J. exp. Psychol., 1951, 41, 216-220.

Hartman, T. F. and Grant, D. A. Effect of intermittent reinforcement on acquisition, extinction, and spontaneous recovery of the conditioned eyelid resoonse. J. exp. Psychol., 1960, 60, 89-96.

Fumphreys, L. G. The effect of random altemation of reinforcement on the acquisition and extinction of conditioned eyelid reactions. J. exp. Psychol., 1939, 25, 141-158.

Humphreys, I. G. Measures of strength of conditioned eyelid responses. J. gen. Psychol.. 1943, 29, 101-111.

Jenkins. H. M. Resistence to extinction when partial reinforcement is followed by regular reinforcement. J. exp. Psychol., 1962, 64. $441-450$. 
Lawrence, D. $\mathrm{K}$. and Festinger, L. Deterrents and Reinforcement. Stanford: Stanford Iniversity Pross. 1962. Iogan. F. A. A note on stimulus intensity dynamism (V). Psychol.
Rev., 1954, 61, 77-80.

Mattson. M. and Moore, J.W. Intertrial responding and CS iniensity in classical eyelid conditioning. J. exp. Psychol.. 1964 (in press).

McAllister, W. R. The effect on eyelid conditioning of shifting the CS-UCS interval. J. exp. Psychol.. 1953, 45, 423-428.

Moore, J. W. and Gormezano. I. Effects of omitted versus delayed uCS on classical eyeltd conditioning under partial reinforcercent. J. exp. Psychol., 1963, 65, 249-250.

Quartermain, D. and Vaughan, G. M. Fffect of interpolating continuous reinforcement between partial training and extinction. Psychol. Rep.. 1961, 8, 235-237.

Quartermain, D., Vaughan, G. M., and Mangan, G. The effects of continuous following partial reinforcement on resistence to extinction. Austr. J. Psychol.. 1961.

Ross, I. E. Decremental effects of partial reiniorcement during acquisition of the conditioned ejelid response. J. exp. Psychol.. 1959. 57. 74-82.

Spence, K. W. A theory of emotionally based drive (D) and its relation to performance in simple learning situations. Amer. Psychol., 1958, 13, 131-142.

Spence, K. W. Cognitive factors in the extinction of the conditioned eyelid response in humans. Science, 1963, 140, 1224-1225.

Spence, K. W., Rutledge, E. F.. and Talbott, J.H. Effect of number of acquisition trials and the presence or absence of the UCS on extinction of the eyelid CR. J. exp. Psychol., 1963, 66, 286-291.

Theois, J. The partial reinforcement effect sustained through blocks of continuous reinforcement. J. exp. Psychol., 1962, 64, 1-6. 
Appendix A

Instructions

riease iisten care fully to the following instructions. Remain seated comfortably and keep looking in front of you. Do not touch anything on your head at any tiree during the experiment. You will hear and feel a series of stimuli during the experimental session. Be careful not to control voluntarily your natural reactions to the stimuli. Do not try to figure out the experiment. Keep as detached an attitude as possible and simply let your reactions take care of themselves.

You can communicate with me at any time by speaking in a normal voice. Are these instmuctions perfectly clear to you? 


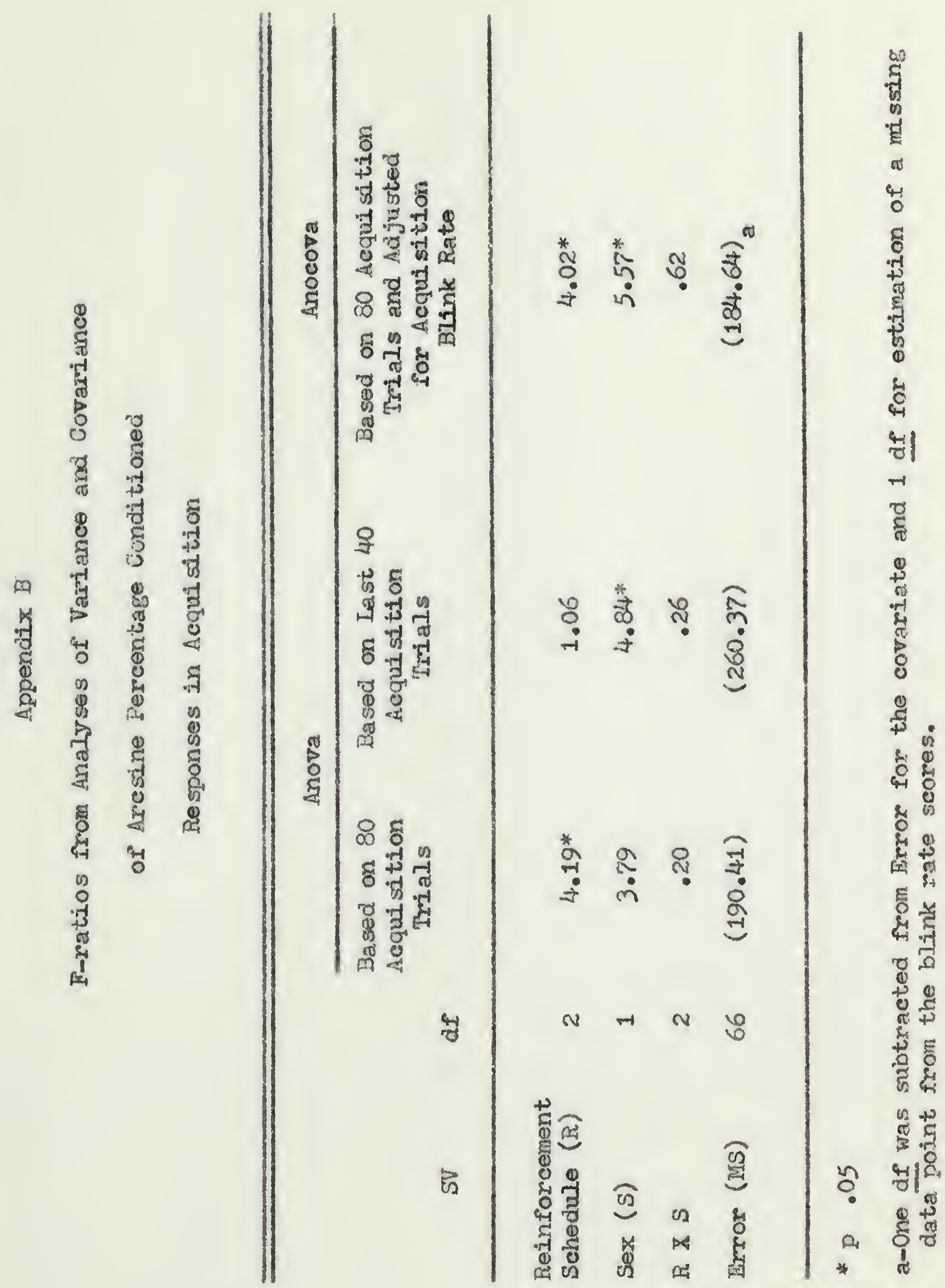




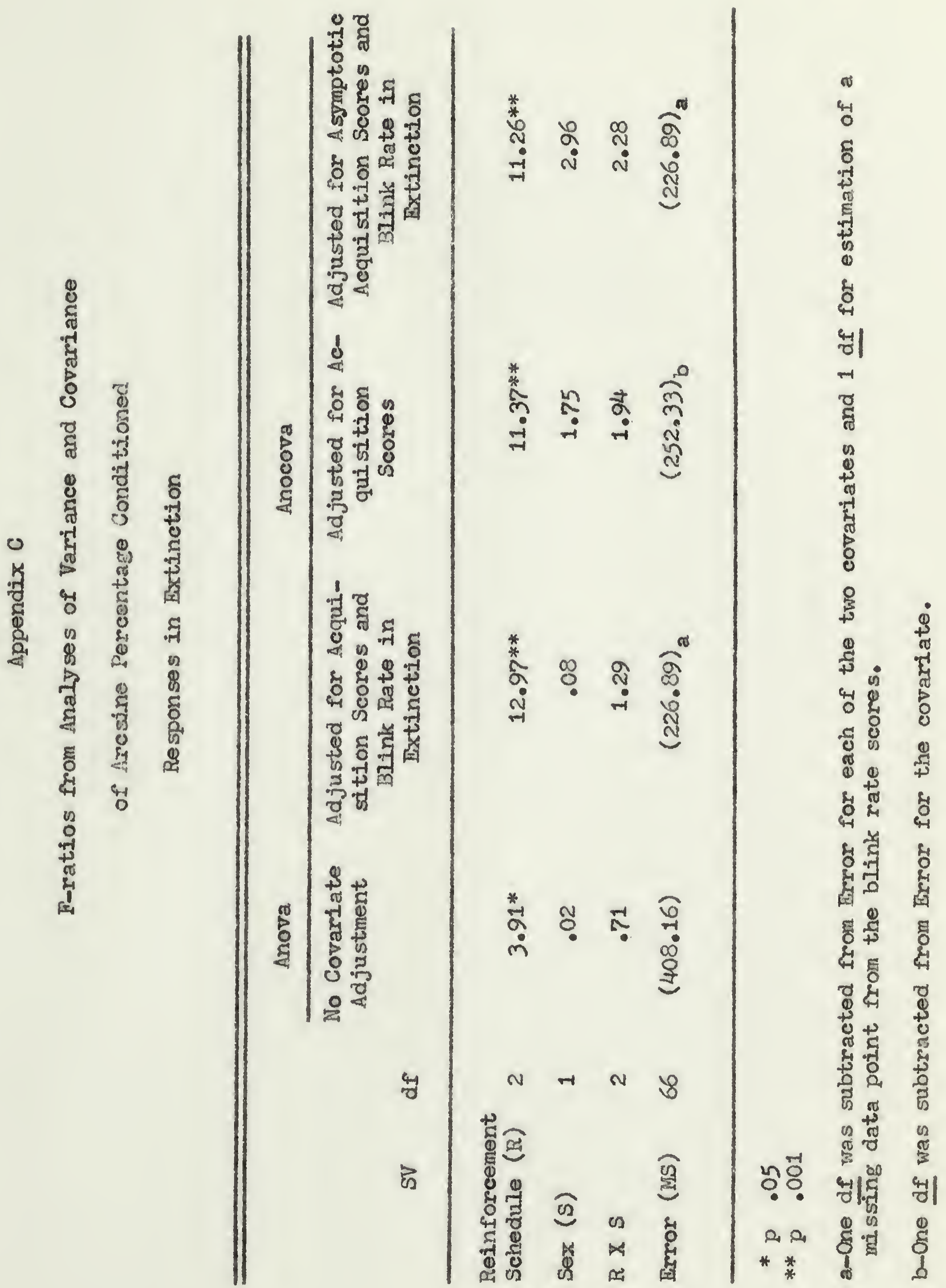


20.

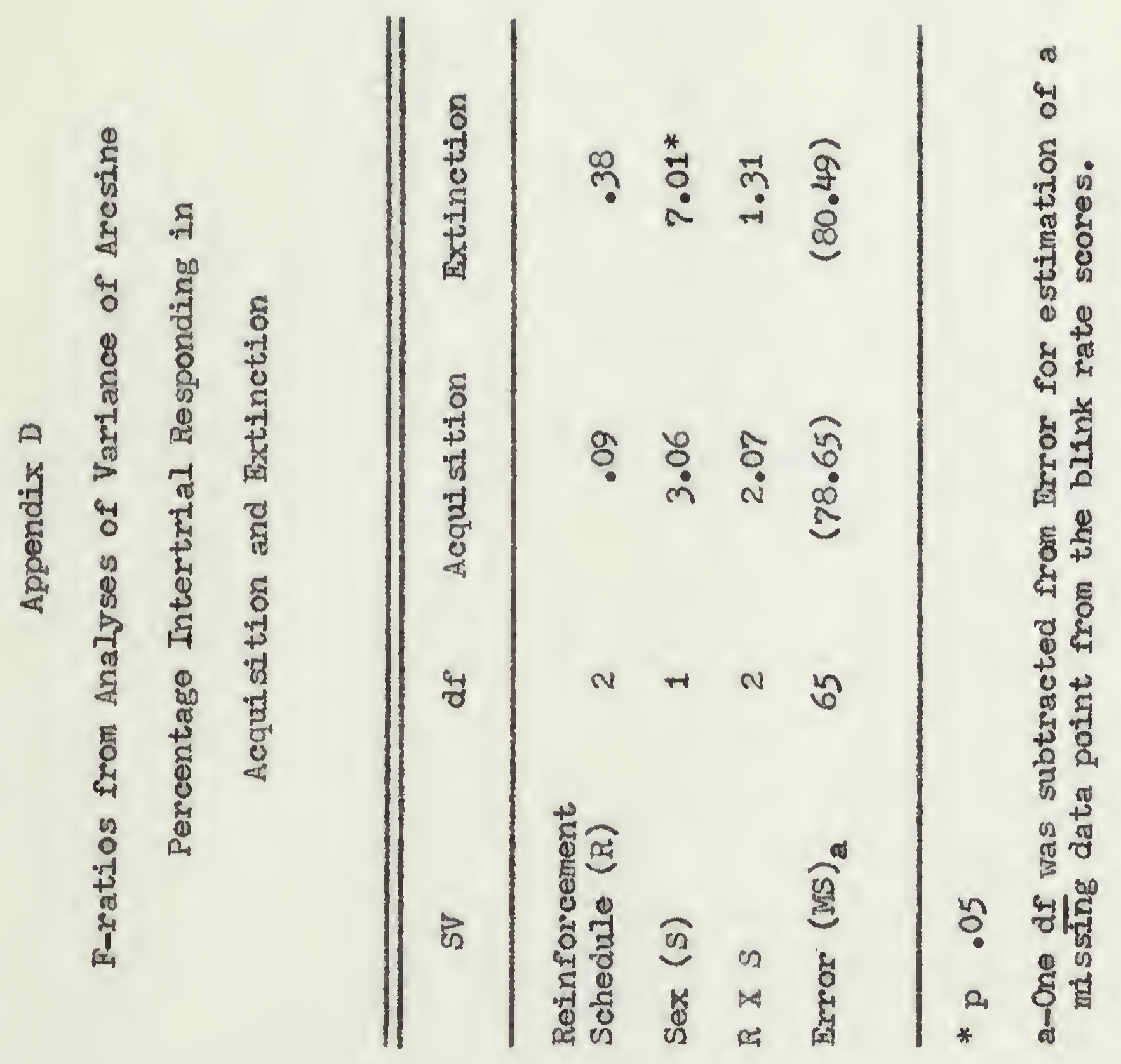




\section{Appendix Ea}

Percentage CRs and Intertrial Responses (BR)

for Subjects in Group $50-50$

\begin{tabular}{|c|c|c|c|c|c|c|c|c|}
\hline \multirow{3}{*}{$\underline{S}$} & \multicolumn{4}{|c|}{ Males } & \multicolumn{4}{|c|}{ Fernales } \\
\hline & \multirow{2}{*}{\multicolumn{2}{|c|}{$\begin{array}{l}\text { Acquisition } \\
\text { CRs BR }\end{array}$}} & \multicolumn{2}{|c|}{ Extinction } & \multicolumn{2}{|c|}{ Acquisition } & \multicolumn{2}{|c|}{ Extinction } \\
\hline & & & CRs & $\mathrm{BR}$ & CRs & $B R$ & & $B R$ \\
\hline 1. & 75.0 & 57.5 & 75.0 & 51.5 & 42.5 & 5.7 & 15.0 & 1.9 \\
\hline 2. & 65.0 & 25.6 & 50.0 & 9.7 & 55.0 & 13.6 & 10.0 & 17.7 \\
\hline 3. & 95.0 & 12.0 & 95.0 & 7.3 & 63.8 & 37.1 & 20.0 & 33.7 \\
\hline 4. & 70.0 & 10.0 & 55.0 & 5.2 & 21.2 & 12.5 & 10.0 & 8.0 \\
\hline 5. & 68.8 & 10.6 & 40.0 & $2 . ?$ & 36.2 & 10.2 & 30.0 & 11.1 \\
\hline 6. & 47.5 & 19.4 & 30.0 & 12.5 & 46.2 & 35.5 & 100.0 & 28.1 \\
\hline 7. & 58.8 & 16.9 & 65.0 & 12.4 & 78.8 & 19.5 & 65.0 & 20.4 \\
\hline 8. & 63.8 & 24.0 & 25.0 & 19.2 & 33.8 & 12.3 & 30.0 & 9.0 \\
\hline 9. & 77.5 & 12.2 & 50.0 & 14.4 & 75.0 & 21.2 & 85.0 & 29.0 \\
\hline 10. & 15.0 & 20.6 & 15.0 & 14.3 & 21.2 & 8.5 & 10.0 & 8.9 \\
\hline 11. & 8.8 & 8.5 & 15.0 & 11.5 & 76.2 & 25.5 & 95.0 & 23.5 \\
\hline 12. & 48.8 & 29.2 & 25.0 & 20.9 & 51.2 & 23.0 & 25.0 & 13.3 \\
\hline
\end{tabular}


Appendix Eb

Percentage CRs and Intertriel Responses (BR)

for Subjects in Croup 50-100

\begin{tabular}{|c|c|c|c|c|c|c|c|c|}
\hline \multirow{3}{*}{$\underline{S}$} & \multicolumn{4}{|c|}{ Males } & \multicolumn{4}{|c|}{ Females } \\
\hline & \multicolumn{2}{|c|}{ Acquisition } & \multicolumn{2}{|c|}{ Extinetion } & \multicolumn{2}{|c|}{ Acquisition } & \multicolumn{2}{|c|}{ Extinction } \\
\hline & CRS & ER & CRs & $B R$ & CRS & $B R$ & CRs & BR \\
\hline 1. & 91.2 & 44.7 & 15.0 & 4.2 & 45.0 & 28.7 & 25.0 & 12.1 \\
\hline 2. & 71.2 & 17.3 & 70.0 & 6.2 & 26.2 & 22.5 & 10.0 & 17.1 \\
\hline 3. & 47.5 & 15.2 & 30.0 & 9.8 & 46.2 & 25.3 & 15.0 & 22.9 \\
\hline 4. & 27.5 & 3.8 & 15.0 & 1.7 & 66.2 & 10.8 & 80.0 & 15.4 \\
\hline 5. & 35.0 & 19.4 & 50.0 & 27.6 & 57.5 & 17.3 & 20.0 & 11.9 \\
\hline 6. & 43.8 & 16.4 & 10.0 & 17.9 & 37.5 & 20.8 & 20.0 & 5.7 \\
\hline 7. & 60.0 & 28.6 & 50.0 & 24.6 & 68.8 & 53.2 & 60.0 & 47.7 \\
\hline 8. & 58.8 & 7.7 & 20.0 & 3.7 & 41.2 & 3.0 & 10.0 & 1.8 \\
\hline 9. & 78.8 & 32.2 & 95.0 & 30.2 & 93.8 & 17.2 & 45.0 & 13.4 \\
\hline 10. & 21.2 & 3.0 & 00.0 & .9 & 23.8 & 24.8 & 10.0 & 26.1 \\
\hline 11. & 20.0 & 10.7 & 00.0 & 5.8 & 25.0 & 19.2 & 30.0 & 9.9 \\
\hline 12. & 80.0 & 16.5 & 100.0 & 10.5 & 7.5 & 28.1 & 00.0 & 15.2 \\
\hline
\end{tabular}


Appendix Ee

Percentage CRs and Intertrial Respnses (BR)

for Subjects in Groups 100-100

\begin{tabular}{|c|c|c|c|c|c|c|c|c|}
\hline \multirow{3}{*}{$\underline{s}$} & \multicolumn{4}{|c|}{ Males } & \multicolumn{4}{|c|}{ Females } \\
\hline & \multirow{2}{*}{\multicolumn{2}{|c|}{$\begin{array}{l}\text { Acquisition } \\
\text { CPs }\end{array}$}} & \multicolumn{2}{|c|}{ Extinction } & \multicolumn{2}{|c|}{ Acquisition } & \multicolumn{2}{|c|}{ Extinction } \\
\hline & & $\mathrm{BR}$ & CRs & $\mathrm{BR}$ & CRs & $B R$ & CRs & $B R$ \\
\hline I. & 82.5 & 6.6 & 10.0 & 5.6 & 86.2 & 16.0 & 25.0 & 9.0 \\
\hline 2. & 63.8 & 20.6 & 40.0 & 17.1 & 73.8 & 21.0 & 75.0 & 19.8 \\
\hline 3. & 67.5 & $-\infty$ & 20.0 & - & 48.8 & 26.7 & 70.0 & 24.4 \\
\hline 4. & 93.8 & 7.6 & 10.0 & .9 & 47.5 & 11.0 & 00.0 & 22.0 \\
\hline 5. & 67.5 & 8.3 & 20.0 & 5.2 & 33.8 & 44.2 & 20.0 & 15.8 \\
\hline 6. & 67.5 & 11.8 & 10.0 & 10.1 & 86.2 & 55.1 & 60.0 & 51.2 \\
\hline 7. & 83.8 & 18.1 & 15.0 & 2.3 & 40.0 & 20.8 & 5.0 & 17.1 \\
\hline 8. & 91.2 & 30.1 & 30.0 & 21.6 & 63.8 & 15.3 & 10.0 & 6.2 \\
\hline 9. & 91.2 & 25.3 & 35.0 & 24.7 & 58.8 & 57.6 & 10.0 & 32.8 \\
\hline 10. & 80.0 & 6.4 & 15.0 & 4.9 & 75.0 & 9.4 & 25.0 & 2.2 \\
\hline 11. & 63.8 & 5.9 & 00.0 & .3 & 43.8 & 35.6 & 5.0 & 35.4 \\
\hline 12. & 33.8 & 16.1 & 00.0 & 9.6 & 57.5 & 13.6 & 30.0 & 15.8 \\
\hline
\end{tabular}




\section{Acknowledgments}

The author wishes to express gratitude to Dr. Iouis E. Price for his cooperation and guidance during the course of this study and especially for his encouragement and understanding throughout my graduate and undergraduate training.

Special appreciation is extended to Dr. John W. Moore, chairman of the thesis cormittee. whose suggestions and assistance were largely responsible for the completion of this study. Thanks are extended to Dr. Ralph R. Pippert for serving as a thesis committe member. 
Approved by :

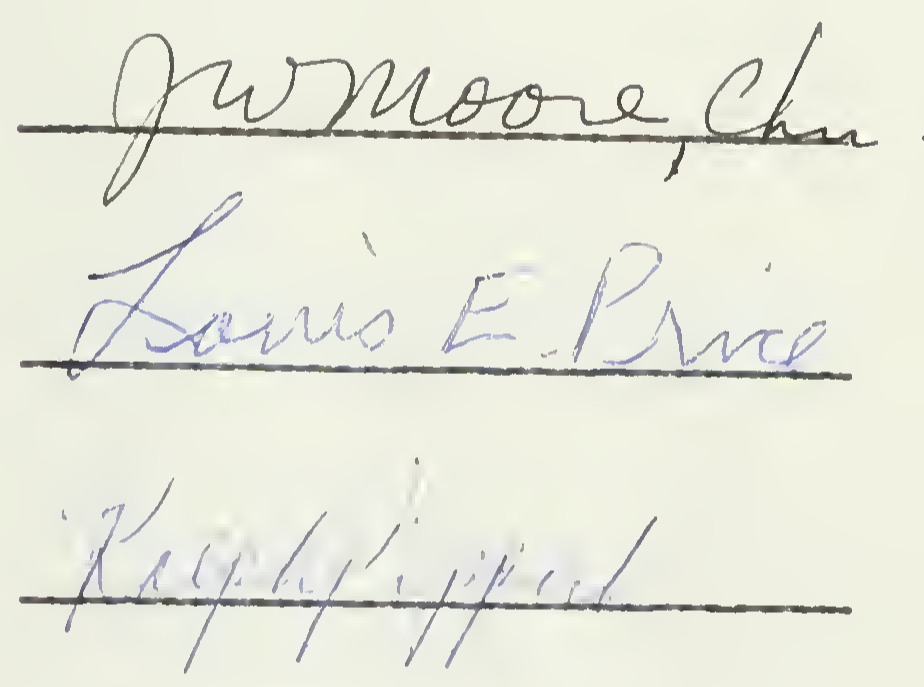

Date: Mov.30,1963 


\section{(1)}

(1)

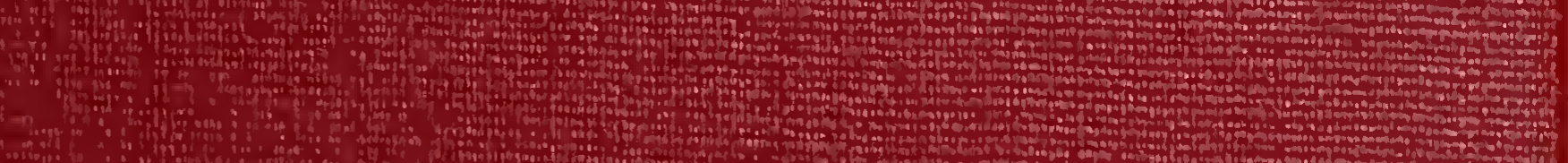

1.1 34 .

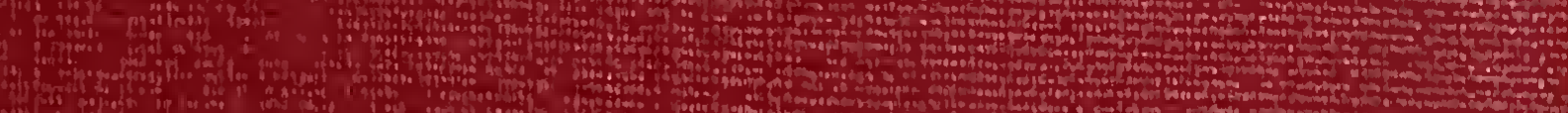
1. 40

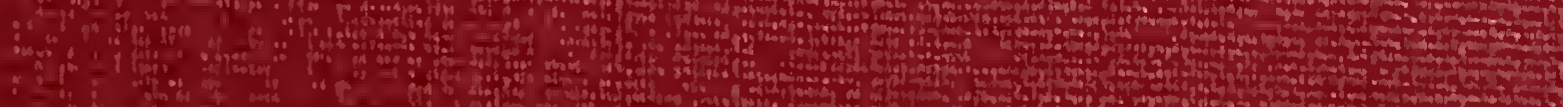

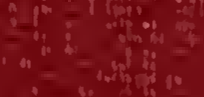
(1) How To 140.040

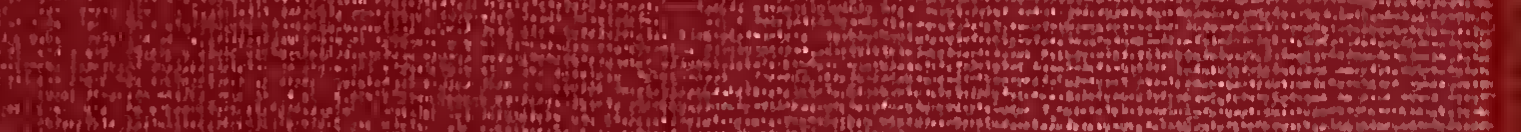
169.

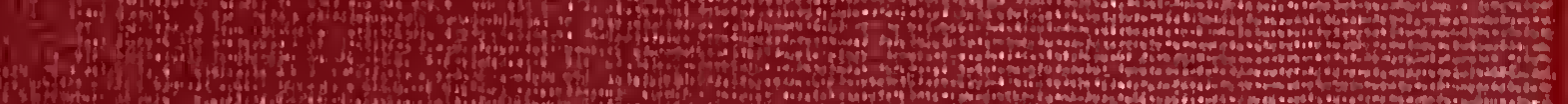

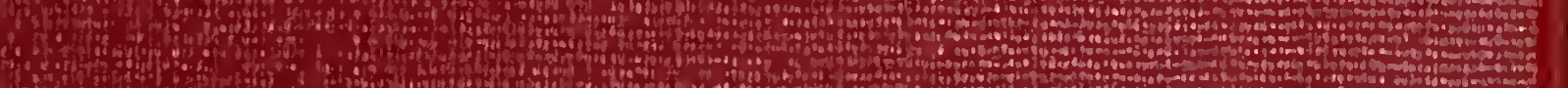
(1) for

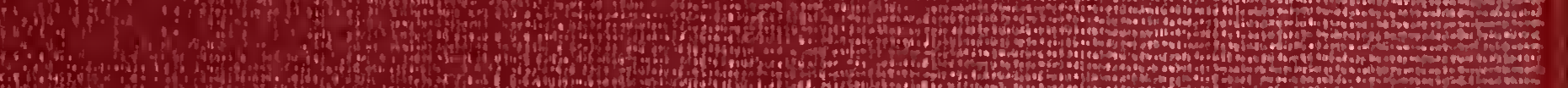

